\title{
Compromissos Éticos e Responsabilidade Social: Ferramentas de Gestão para o Setor Moveleiro do Estado de Santa Catarina
}

\section{Ethical Commitments and Social Responsibility: Management} Tools for the Furniture Sector of Santa Catarina State

\author{
Cristiane Maria Cutas \\ Alexandre Borges Fagundes \\ Maclóvia Corrêa da Silva \\ Nadir Radoll Cordeiro
}

\section{Resumo}

A responsabilidade social pode ser vista hoje, como uma nova forma de gestão, um instrumento para melhorar e consolidar a imagem das organizações, para a abertura de novos mercados e para angariar maior competitividade no mercado globalizado. Várias empresas, nacionais e internacionais, possuem visões ampliadas deste aspecto, considerando a importância das ações para melhorar o bem estar das comunidades em que estão inseridas, dos potenciais colaboradores, das necessidades de preservar e conservar o meio ambiente, e dos papéis dos stakeholders com respeito ao desempenho econômico, com os investimentos e com os retornos financeiros, ambientais e humanos. Observa-se, no atual cenário, que empresas e consumidores buscam a qualidade não somente dos produtos, mas também das ações decorrentes desta atividade. As oportunidades de comercialização no mercado tendem a privilegiar os produtos e os serviços oriundos de indústrias que respeitem os princípios éticos, que são socialmente responsáveis, privilegiem as tecnologias limpas e ao alcance de consumidores desejosos de encontrar um diferencial na imagem e na visibilidade das empresas e dos produtos. Neste sentido caminham as idéias deste artigo, que buscou analisar as ações voltadas à Responsabilidade Social nas indústrias de móveis de um município localizado no interior do estado de Santa Catarina. Apesar de pertencer ao maior parque fabril do estado, no segmento moveleiro, e fazer parte do maior pólo exportador de móveis do Brasil, constatou-se que as ações empresariais relacionadas às práticas de Responsabilidade Social apresentam-se ainda em processo de construção, carecendo de formação de consciência e de mecanismos para gestão de atitudes e comportamentos. A pesquisa compôs-se de referencial teórico e de pesquisa de campo que contribuíram para um melhor entendimento sobre o tema da ética e da Responsabilidade Social, seus aspectos históricos e 
epistemológicos. A análise e estudo crítico das respostas a questionários propostos para as empresas selecionadas permitiram delinear um panorama de como elas estão lidando com estas questões. Por meio dos resultados conhecidos com a pesquisa de campo e do estudo bibliográfico foi possível situar em que estágio de compreensão encontram-se as empresas com respeito aos compromissos éticos e à responsabilidade social. Ainda faz-se mister trabalhar com estes parâmetros de modo que seja possível traçar estratégias que lhes despertem novos significados no sentido de se contextualizarem como partes atuantes do desejável desenvolvimento equitativo e sustentável para uma sociedade diversa e diferente dos primórdios da industrialização.

Palavras-chave: Responsabilidade Social; Ética; Empresa; Indústria Moveleira; Santa Catarina.

\section{Abstract}

Social responsibility can be seen today as a new form of management, a tool to improve and consolidate the image of organizations, for the opening of new markets and to gain greater competitiveness in the global market. Several companies, national and international, have enlarged views of this aspect, considering the importance of actions to improve the welfare of the communities in which they operate, potential employees, needs to preserve and conserve the environment, and roles of stakeholders with respect to economic, with investment returns and the financial, environmental and human. It is observed in the current scenario, businesses and consumers to look for quality not only of products but also actions resulting from this activity. Marketing opportunities in the market tend to focus on products and services from industries that the ethical principles that are socially responsible, focusing on the clean technology and the reach of consumers eager to find a difference in image and visibility of businesses and products. In this sense the ideas go this paper, which investigates the actions focused on Social Responsibility in the furniture of a municipality located in the state of Santa Catarina. Despite belonging to the largest industrial park in the state, in the furniture segment, and part of the largest furniture export hub of Brazil, it was found that the actions related to corporate social responsibility practices are presented also in process of construction, lacking awareness training and mechanisms for management of attitudes and behaviors. The survey was composed of theoretical and field research that contributed to a better understanding on the topic of ethics and social responsibility, its historical and epistemological. The analysis and critical study of responses to questionnaires proposed for the selected companies allowed us to delineate a picture of how they are dealing with these issues. Through the known results with the field survey and literature research was possible to point at what stage of understanding are the companies with respect to the ethical commitment and social responsibility. Yet it is essential to work with these parameters so that it is possible to devise strategies they awaken new meanings in order to contextualize acting as parts of desirable equitable and 
sustainable development for a diverse and different from the beginnings of industrialization.

Keywords: Social Responsibility, Ethics, Company, Furniture Industry, Santa Catarina.

\section{Introdução}

Com o crescimento da produção de bens, a partir da Revolução Industrial, a organização social foi se modificando, sobretudo no que diz respeito aos hábitos de consumo e a migração das populações do campo para as cidades. O contínuo desenvolvimento de técnicas, e a sua conseqüente incorporação às máquinas, permitiram a ampliação dos volumes de produção de bens, a redução de custos, a especialização de mão-de-obra e a participação da ciência como motivadora do desenvolvimento tecnológico.

Inicialmente, a industrialização inglesa provocou o fechamento dos campos e a migração de trabalhadores, o que representou para os dirigentes ter que lidar com novos problemas como as superpopulações e a pouca infra-estrutura habitacional, de circulação, e de lazer no espaço urbano. A produção industrial demandava uma grande quantidade de mãode-obra, a qual se encontrava dispersa no país, dedicando-se às atividades agrícolas e sem a intenção de abandonar suas práticas cotidianas. Aqueles que podiam manter-se no campo e na cidade o faziam, e os que não puderam manter os laços com a vida campestre, amontoaram-se nas cidades.

O crescimento inesperado de determinadas cidades (Manchester, Liverpool, Londres) contrastava com a quantidade de problemas sociais, ambientais, culturais provocados pela incapacidade da economia de atender as necessidades básicas de grande parcela da sociedade civil. Este quadro assemelha-se ao de outros países que seguiram esta política de produção de bens. Ainda na atualidade, muitas indústrias trabalham de modo isolado, sem manter diálogos com os setores públicos ou sem o compromisso de assumir as "clamadas" responsabilidades sociais.

A promoção da globalização iniciada nos anos 1980 e o desmonte do Estado do bem estar social são marcos diferenciais no que diz respeito às atribuições das indústrias. As oportunidades de promoção positiva dos negócios, e a melhor aceitação dos produtos e serviços no mercado implicam em diálogos com os consumidores. O setor privado, ao participar da resolução de impasses, deixou de ser paternalista ou de fazer filantropia. Ele trabalha em conjunto com os seus interesses e metas e aqueles dos consumidores. As estratégias de negócios das organizações contêm os investimentos sociais que são tratados como qualquer outro investimento, e que são considerados essenciais para a expansão dos lucros, para competir e sobreviver no mercado.

Estes procedimentos podem ser explicados pela crescente tomada de consciência dos consumidores, que cada vez mais, com a ajuda das tecnologias da informação, dão preferência por produtos e práticas que produzam melhorias para a comunidade, o meio ambiente, e privilegiem as condutas éticas e a transparência das organizações. No Brasil, que 
desencadeou seu processo de industrialização com a ditadura de Getúlio Vargas (1937-1945 e 1950- 1954), na qual teve início a preparação das infra-estruturas de base, viárias, energéticas e hidráulicas e a regulamentação do trabalho assalariado, as desigualdades sociais e regionais acentuaram-se com a concentração de empresas na região sul e sudeste do país. De acordo com Laboissière e Cavalcante (2010), o Brasil apresenta o terceiro pior índice de desigualdade social da América Latina e Caribe, ficando abaixo apenas da Bolívia e do Haiti.

Para o Instituto Ethos (2010) estas grandes carências e desigualdades sociais que se distribuem pelo solo brasileiro precisam ser argumentos representativos para aumentar os diálogos entre setores públicos e privados no que tange à responsabilidade social empresarial: a "sociedade brasileira espera que as empresas cumpram um novo papel no processo de desenvolvimento: sejam agentes de uma nova cultura, sejam atores de mudança social, sejam construtores de uma sociedade melhor".

O governo vem pouco a pouco direcionando as ações das empresas neste sentido, de modo a estimular ações e estratégias de negócios que incluam a responsabilidade social nos processos de gestão como uma ferramenta para aumentar as interações com os consumidores, a competitividade e expandir os ganhos financeiros, ambientais, culturais e sociais. Neste artigo pretende-se conhecer como isto vem ocorrendo em Santa Catarina, no segmento moveleiro, e como este estudo pode contribuir, por meio do estudo bibliográfico, para aumentar a compreensão do tema e delinear posturas mais impactantes e benéficas para a sociedade.

\section{Responsabilidade Social: histórico e definição}

Nas últimas décadas, os termos responsabilidade social e ética vêm ganhando destaque no mundo empresarial. Na verdade, o Estado contribuiu com capital social para que elas crescessem, e com a mundialização das indústrias, a competitividade e rentabilidade dos investimentos a demanda por contrapartida se faz premente. A importância desse compromisso na postura das organizações e sua influência nos objetivos e estratégias de gestão das empresas são cada vez mais urgentes para que os diálogos aumentem entre setor privado, setor público e a sociedade.

Cavalcanti (2006, p.76) explica que, em até meados dos anos 1970 , não havia nenhum tipo de exigência governamental para com o empresariado brasileiro no sentido de colaborar com a mitigação das desigualdades sociais. Era um compromisso do Estado a resolução dos problemas decorrentes do processo industrial e da urbanização acelerada e desordenada. Ou seja, todos estavam envolvidos com as questões de miséria, de falta de moradia, de saúde, de educação, mas poucos disponibilizavam recursos e investimentos para introduzir mudanças no processo de desenvolvimento do país.

No contexto mundial, segundo Zarpelon (2006), não se pode ainda situar historicamente 0 início dos estudos sobre o tema da Responsabilidade Social. Uma data importante que marcou o início de 
novas formas de pensar a produção, o trabalho, a cidadania e a vida socioeconômica, e que provavelmente tratou das questões éticas e de responsabilidade social, é a Revolução Francesa em 1789. Com a queda do regime monárquico marcada pela destruição do imóvel representativo da opressão e do autoritarismo (la Bastille) e a Declaração dos Direitos do Homem e do Cidadão desencadearam ações de libertação de colônias, melhores condições de produção para os artesãos e aperfeiçoamento de técnicas de manufaturas.

Pode-se também atribuir os efeitos da Revolução Industrial como fator de grande influência nas discussões sobre o tema Responsabilidade Social, já presente nos anos 1750 no norte da Itália, Alemanha e França, que, segundo Zarpelon (2006), introduziu novas técnicas e modelos produtivos. Muitos trabalhadores e trabalhadoras deslocaram-se do campo para atender a demanda de mão-de-obra concentrada nas cidades, as quais não tinham infraestrutura social e habitacional para acomodar as novas populações.

Um documento que embasou as discussões sobre desigualdades, ética e responsabilidade social, e que tem representatividade mundial é a Declaração Universal dos Direitos Humanos do século XX. Elaborada pela Organização das Nações Unidas (ONU) em 1948, este texto tem fundamentado legislações, atitudes e procedimentos nas relações humanas entre continentes. Consequentemente, a responsabilidade social, um aspecto importante da Declaração, foi ganhando corpo ao longo dos anos, reforçada por uma seqüência de eventos que passaram por diferentes estágios. Inicialmente eles eram compreendidos como caridade, depois como atendimento aos direitos das pessoas e hoje faz parte das práticas empresariais pautadas como ferramentas de gestão e de ética (ZARPELON, 2006).

Entretanto, o desenvolvimento de práticas ditas socialmente responsáveis também é favorecido pelas contrapartidas que são oferecidas às empresas no sentido de participar da resolução de entraves sociais. Deste modo, a finalidade é beneficiar ambos os lados. O Instituto Ethos (2010) não perde de vista estas condições: "a empresa é socialmente responsável quando vai além da obrigação de respeitar as leis, pagar impostos e observar as condições adequadas de segurança e saúde para os trabalhadores, e faz isso por acreditar que assim será uma empresa melhor e estará contribuindo para a construção de uma sociedade mais justa" (p.1).

A empresa concebida nestes ideais, cada qual com suas características, fundamentada em princípios gerais de direitos e deveres, teria "obrigações " " para com a sociedade, assumindo responsabilidades que compreendem a proteção ambiental, projetos filantrópicos e educacionais, planejamento da comunidade, igualdade nas oportunidades de emprego, e outros serviços sociais alinhados aos interesses públicos (DONAIRE, 1999). O autor ressalta que a Responsabilidade Social intensificou-se a partir dos anos $1960 \mathrm{com}$ as mudanças de valores da sociedade de consumo. Como se existisse um contrato social entre ambas, a empresa tem liberdade para trabalhar por seus objetivos e como contrapartida, ela precisa contribuir para com o desenvolvimento equitativo das comunidades de seu entorno. 
Os termos deste suposto "contrato" vêm sofrendo alterações substantivas que podem ser imediatamente readaptadas, sobretudo pelas empresas que buscam apenas o crescimento econômico e põem em risco a viabilidade de minimizar os danos compatíveis com a atividade produtiva que representam custos sociais para todos. Assim, diferente do que se pensava anteriormente, o crescimento econômico não está ligado somente ao progresso socioeconômico, pois em várias situações, dele decorre uma gama muito ampla de fatores negativos: devastação física do ambiente, poluição, desigualdades, condições insalubres de trabalho, e outras. $\mathrm{Na}$ medida em que se adicionam novos termos a este contrato "representativo", sanando carências e deficiências, dá-se a redução de custos sociais provocados pelas empresas e certa coerência com as abordagens do crescimento econômico no contexto da sustentabilidade.

Além disso, aspectos éticos alargam os limites das dimensões sociais das atividades produtivas e reorientam os sistemas de poder e as relações de força entre os grupos. Impõem-se novos significados para as condições de bem-estar dignas de serem reproduzidas. Zarpelon (2006, p.15), ao definir responsabilidade social, Ihe dá um valor institucional e global:

\begin{abstract}
Responsabilidade social é a responsabilidade assumida diante da sociedade, em relação à geração de empregos, a pagamentos de salários dignos, à arrecadação correta da carga tributária, ao aumento da qualidade de vida, à assimilação e transferência de tecnologia ou qualquer outro fator que possa agregar benefício para a gestão e para a sociedade.
\end{abstract}

A responsabilidade social praticada pelas empresas pode ocorrer internamente, quando a ação recai sobre os colaboradores que pertencem ao quadro da própria empresa, ou externamente, com a comunidade do entorno onde ela que está inserida. O ideal é que a empresa atenda os dois ambientes, interno e externo, compreendendo a importância de investimentos e procedimentos sistêmicos que apresentem um raio de ação mais abrangente para a sociedade e um grau de satisfação micro-social que faça parte de uma única constelação.

\title{
2.1 Responsabilidade Social Corporativa
}

A responsabilidade social corporativa pode ser entendida como a forma que a empresa conduz seus negócios, pautados na ética e no compromisso com seus stakeholders ${ }^{2}$ (partes interessadas). Ela faz parte do planejamento estratégico da empresa e da tomada de decisões. Melo Neto e Froes (1999, p.90) salientam que as novas idéias sobre a responsabilidade social das empresas nasceram na Holanda, em 1998, por ocasião da reunião do Conselho Empresarial Mundial para o Desenvolvimento Sustentável. O objetivo principal deste evento foi realizar uma análise da atuação das empresas no campo social.

Responsabilidade social corporativa é o comprometimento permanente dos empresários de adotar um comportamento ético e contribuir para o desenvolvimento econômico, melhorando, simultaneamente, a 
qualidade de vida de seus empregados e de suas famílias, da comunidade local e da sociedade como um todo (MELO NETO E FROES, 1999, p.90).

Para Cavalcanti (2006), com base em estudos desenvolvidos pelo Banco Nacional de Desenvolvimento Econômico e Social (BNDES) em 2002, o conceito de responsabilidade social corporativa é mais amplo que a responsabilidade social. Aquele está associado ao reconhecimento de que as decisões e os resultados das atividades produtivas das empresas fazem circular e equilibrar os investimentos de modo a beneficiar não somente os sócios e acionistas, mas sim a um universo de agentes sociais envolvidos na dinâmica da exclusão e da inclusão.

A preservação ambiental e o desenvolvimento comunitário são insuficientes para que uma empresa seja considerada socialmente responsável. Ela precisa também realizar investimentos no ambiente de trabalho, praticar o exercício da transparência, e garantir a satisfação de seus consumidores e seus públicos no sentido mais amplo, independentemente dos prejuízos ou ganhos dela decorrente. $\mathrm{Na}$ concepção de Melo Neto e Froes (1999, p.78) "a responsabilidade social de uma empresa consiste na sua decisão de participar mais diretamente das ações comunitárias na região em que está presente e minorar possíveis danos ambientais decorrentes do tipo de atividade que exerce".

$\mathrm{O}$ conceito de responsabilidade social corporativa desenvolvido por Carrol e Buchholtz (2000, p.33; apud Fedato, 2005, p. 26) segmenta e classifica níveis de relações do homem com suas atitudes e posturas a serem transpostas na sociedade. As diferentes abordagens, em quatro estágios, que vão da obrigatoriedade à responsabilidade assumida espontaneamente, pretendem criar uma sustentação entre os eixos estruturantes da pirâmide, como mostra a Figura 1.

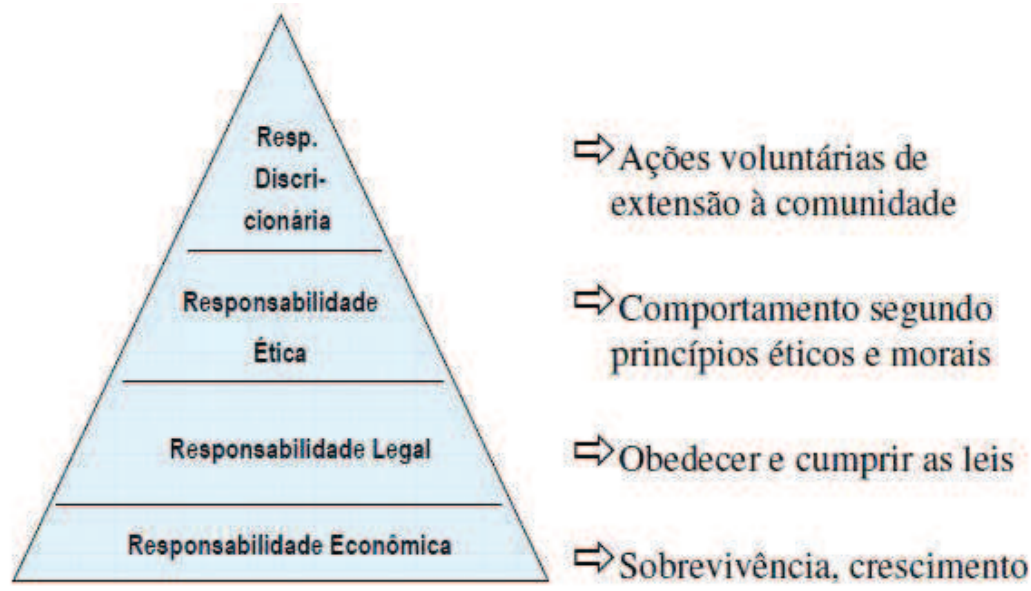

Figura 1 - A pirâmide da responsabilidade social Fonte: adaptado de Carrol e Buchholtz (2000), apud Fedato (2005) 
Conforme os autores, a base da pirâmide, a responsabilidade econômica, é aquela que mantém todas as outras. Isto significa a necessidade que a empresa tem de estar bem estruturada financeiramente para garantir o sucesso dos demais estágios. O segundo nível, o da responsabilidade legal, ressalta a importância da adequação das atividades produtivas às regras, contratos, e legislações. Estes dois patamares da pirâmide estão ligados às condições impostas pela sociedade para o funcionamento normal de uma empresa.

O terceiro nível, o da responsabilidade ética, deixa de ser obrigatório, mas é o que a sociedade almeja da organização Ele "traduz-se em escolhas organizacionais que estejam de acordo com princípios éticos e morais vigentes na cultura social em que a empresa está inserida, levando-a a atuar num patamar acima do requerido por lei no que se refere ao atendimento dos interesses coletivos" (FEDATO, 2005, p.27).

O quarto nível trata do envolvimento da empresa em solucionar os problemas sociais, voluntariamente. Este envolvimento não é reclamado e por vezes nem é esperado, mas é um estágio importante, sobretudo para as comunidades do entorno das indústrias. Segundo Ashley (2005, p.56) "[...] o conceito de responsabilidade social corporativa não pode ser reduzido a uma dimensão social da empresa, mas interpretado por meio de uma visão integrada de dimensões econômicas, ambientais e sociais que, reciprocamente, se relacionam e se definem".

Carrol (1979, p.500; apud Borba, 2005, p.33) faz uma interligação entre os quatro níveis de responsabilidade que possuem tendências a formar a unicidade de posturas, por vezes potencialmente opostas: "a responsabilidade social corporativa dos negócios abrange as expectativas econômicas, legais, éticas e discricionárias que a sociedade possui em relação às organizações em determinado período de tempo."

\section{2 Ética, cultura, moral e Responsabilidade Social}

De acordo com Santos (2010, p.1), "a palavra ética vem do grego ethos que significa: modo de ser, caráter enquanto forma de vida do homem." O autor explica que ética é a maneira como o homem age e se comporta em seu ambiente social, praticando relações inter-sociais que implicam em um comportamento moral com aceitação no meio em que vive.

A sociedade guia-se por princípios e valores culturais, os quais definem comportamentos, atitudes de grupos, indivíduos e organizações. Pode-se dizer que a cultura organizacional baseada em princípios éticos, em concepções, interesses e necessidades, influencia no entendimento da responsabilidade social corporativa, pois estes, bem como os valores culturais, definem as vertentes de responsabilidade social implementados pelas organizações (ASHLEY, 2005).

Ashley (2005) explica que a ética, valores morais e cultura são conceitos que conferem visibilidade para a responsabilidade social empresarial. São necessários para a definição de critérios e parâmetros apropriados ao desenvolvimento das atividades de responsabilidade social nas empresas. Para a autora, atualmente as organizações devem 
preocupar-se, além de suas responsabilidades econômicas e legais, com as responsabilidades éticas, morais e sociais, as quais equivalem aos diferentes tipos atividades, comportamentos, políticas e práticas, desejados ou vedados pela sociedade: "estas responsabilidades éticas correspondem a valores morais específicos. Valores morais dizem respeito a crenças pessoais sobre comportamento eticamente correto ou incorreto, tanto por parte do próprio indivíduo quanto com relação aos outros" (p.5).

A identificação de contributos decisivos para fundamentar ideários do comportamento ético e enfrentar os paradoxos e ambiguidades das propostas e intervenções para ações de responsabilidade social corporativa são capazes de suscitar relações mais harmoniosas entre os setores da economia. A operacionalização dos pressupostos de um comportamento socialmente responsável por parte das empresas pode colaborar para expandir os negócios. Pode-se dizer que "[...] está se tornando hegemônica a visão de que os negócios devem ser feitos de forma ética, obedecendo a rigorosos valores morais, de acordo com comportamentos cada vez mais universalmente aceitos como apropriados" (ASHLEY, 2005, p.7).

Hoje, é frequente a menção de códigos de ética para reger os atos das empresas. Eles abordam questões comportamentais, estabelecem normas, mas resta discutir como eles são reconhecidos e interpretados pelos grupos que estão envolvidos. Os códigos apontam as direções dos caminhos a serem seguidos, e paralelamente deve acontecer a tomada de consciência a qual permite a posse e a apropriação de novos saberes e conhecimentos pelos membros da organização e da comunidade do entorno. Os representantes de todos os níveis funcionais e gerenciais precisam estimular a comunicação entre as pessoas da organização e os conteúdos do código, que tipificam os discursos e as ações que visam adquirir outra visibilidade, amplitude e coerência da empresa com o processo de desenvolvimento sustentável (ASHLEY, 2005, p.21).

\section{Metodologia}

A pesquisa de campo, com levantamento de dados é de natureza aplicada, sendo considerada descritiva por seus objetivos, e quantitativa pela sua abordagem. Os procedimentos técnicos aplicados foram primeiramente de pesquisa bibliográfica seguida de coleta de dados (GIL, 2002; MENEZES E SILVA, 2005; LAKATOS E MARCONI, 2006). O município do interior do estado de Santa Catarina equipado com um parque fabril de grande porte, foi o espaço de estudo. Está ali presente uma série de indústrias moveleiras que representam grande parte do parque nacional no ramo.

O universo selecionado foi de 14 empresas do segmento moveleiro, contatadas inicialmente por telefone para esclarecimentos dos objetivos da pesquisa, e depois por correio eletrônico. Foi aplicado um questionário no período de novembro de 2010 a janeiro de 2011, e oito delas o responderam por e-mail.

$O$ instrumento de pesquisa para o levantamento dos dados continha perguntas abertas e fechadas (FACHIN, 2005; LAKATOS E MARCONI, 2006). Este visou avaliar o nível das ações empresariais relacionadas à 
prática da Responsabilidade Social. Para isso, foram solicitadas, além das informações quanto a caracterização das empresas, informações referentes a seus valores, transparência, e também estado de comprometimento social.

A validação dos questionários pôde ser feita baseada no próprio feed back das empresas respondentes, que interpretaram as perguntas de forma desejada, assim atingindo os objetivos para os quais foram elaborados.

\section{Resultados da pesquisa}

Sabe-se que o crescente interesse das empresas em investir nas questões sociais é resultado de uma série de fatores - crescimento, competitividade, legislações - que as levaram a rever os impactos de suas atividades na comunidade em que estão inseridas. Com a adoção de uma postura mais ética e socialmente responsável, estas empresas estão garantindo, além do bem estar social, a melhora de sua imagem, e consequentemente de sua competitividade no mercado.

Diante desta realidade, a pesquisa realizada buscou dados a fim de verificar as práticas das empresas produtoras de móveis localizadas no interior de Santa Catarina, relacionadas aos seus valores, compromissos éticos e responsabilidade. Segundo Ashley (2005, p.5), a ética, valores morais e cultura, são conceitos totalmente ligados a qualquer idéia de responsabilidade social empresarial, pois são necessários na instituição de critérios e parâmetros apropriados para o desenvolvimento das atividades de responsabilidade social nas empresas.

Observou-se, com base no critério do IBGE (SEBRAE, 2011) para classificação do porte das empresas por número de funcionários, que 37,5\% das empresas pesquisadas são de pequeno porte, com igual percentual para as de médio porte, e $25 \%$ são de grande porte.

Quanto aos valores e transparência das empresas pesquisadas, $62,5 \%$ delas afirmaram possuir um código de ética que expressa seus valores e princípios, enquanto que $37,5 \%$ afirmaram não possuir. O código de ética, um documento que formaliza os valores da empresa, aponta sua posição e comprometimento social. É positivo o fato da maioria das empresas pesquisadas possuí-lo. Segundo o Instituto Ethos (2011), "o código de ética e/ou de compromisso social e o comprometimento da alta gestão com sua disseminação e cumprimento são as bases de sustentação da empresa socialmente responsável."

Das empresas que afirmaram possuir código de ética (62,5\% do total), elas garantem sua divulgação para todos os seus níveis hierárquicos. Isto pode ser encarado como mais um ponto a favor da empresas pois ele é um instrumento de orientação de posturas e comportamentos considerados ideais.

Ainda entre os $62,5 \%$ das empresas que afirmaram possuir código de ética, $80 \%$ delas afirmaram incorporar seus princípios à cultura do corpo funcional e aos processos de trabalho. Cabe lembrar que o código de ética é formado por um conjunto de normas de conduta profissional e pessoal que norteiam o comportamento de todos que fazem parte de uma 
organização, portanto deve-se promover sua total incorporação à cultura da empresa (envolvendo a totalidade do corpo funcional e processos de trabalho), abrangendo também o comportamento da empresa diante de clientes, parceiros e concorrentes.

Portanto, regras proibindo práticas ilegais para obtenção de vantagens também devem ser explícitas, assim a empresa estará promovendo sua credibilidade e ganhando a confiança de todos com quem mantém relações. Nesse quesito, considerando os $62,5 \%$ das empresas que afirmaram possuir código de ética, apenas $60 \%$ delas afirmaram proibir expressamente práticas ilegais para obtenção de vantagens nos negócios.

Quando perguntado se a organização expõe publicamente - ou seja, para comunidade, governo, cadeia de fornecedores e investidores - seus valores e princípios, apenas 25\% responderam que sim, e $75 \%$ responderam que não, números que demonstram uma situação em que ainda falta a formalização de práticas de responsabilidade social por estas empresas.

Ainda com relação aos valores e transparência das empresas, apenas $12,5 \%$ das que responderam o questionário, indicaram possuir conselhos, comitês ou grupos responsáveis pelas questões éticas, enquanto que $87,5 \%$ não possuem um grupo específico para tratar destas questões. Os comitês, ou conselhos de ética, realizam a avaliação e acompanhamento das questões éticas da organização.

As pessoas possuem valores diferentes, adquiridos durante toda sua vida, e estes podem discordar dos valores da empresa, por isso é necessário que se estabeleça um sistema que regule os princípios de conduta esperados pela empresa, dos seus colaboradores, e estes devem ser monitorados, a fim de se evitar que ações antiéticas venham a acontecer ou a repetir-se. Para que este monitoramento ocorra, o ideal é que se tenha um grupo de profissionais especializados atuando nesta área.

Quanto aos compromissos sociais, as empresas foram questionadas se, além de respeitarem a legislação nacional que proíbe o trabalho antes dos 16 anos, cobram esta mesma postura de sua cadeia de fornecedores ou prestadores de serviços, e de que maneira fazem esta cobrança. Do total da amostra, $50 \%$ responderam que sim, porém apenas duas delas afirmaram solicitar das empresas terceirizadas documentação específica que comprove o registro dos empregados e o pagamento dos mesmos.

Quando perguntado, se a empresa possui projetos que contribuem para 0 desenvolvimento dos filhos de seus empregados, $87,5 \%$ responderam que não. Este é um dado negativo com relação a postura social das empresas pesquisadas. Neste quesito apenas uma empresa respondeu que sim, explicando que possui projeto de menor aprendiz, em parceria com o sindicato do setor.

Capacitar pessoas, é uma forma bastante viável de praticar responsabilidade social, sem contar que os custos para apoiar este tipo de projetos podem ser reduzidos através de parcerias com instituições públicas, ONGs ou mesmo com outras empresas. Assim este tipo de investimento poderia trazer um retorno considerável a essas empresas, que além de estarem colaborando com as demandas da sociedade (e 
possivelmente das próprias empresas), estariam promovendo um ambiente de trabalho com um fator a mais de satisfação, por parte dos genitores ou responsáveis destes jovens.

Como na questão anterior, $87,5 \%$ das empresas também revelou não apoiar projetos focados para as crianças e adolescentes das comunidades do entorno. Estes números podem ser interpretados como um baixo comprometimento das empresas para com o desenvolvimento da comunidade, fator de muita importância na gestão socialmente responsável.

Ainda sobre o compromisso social das empresas, foi perguntado se estas possuem políticas formais com o objetivo de contribuir para a erradicação do trabalho infantil e do trabalho forçado, discutindo a questão com os fornecedores e estimulando-os a cumprir as leis, e se além de discutir o tema, os contratos feitos com os fornecedores possuem cláusulas específicas relativas à proibição do trabalho infantil ou trabalho forçado.

Os dados revelaram que apenas $25 \%$ das empresas pesquisadas têm políticas para erradicação do trabalho infantil e forçado e incentivam seus fornecedores a cumprir as leis. Nenhuma das empresas especifica a proibição do trabalho infantil ou escravo nos contratos com seus fornecedores.

Esta é uma questão muito importante na visão da responsabilidade social. Uma empresa socialmente comprometida jamais deve utilizar mãode-obra infantil ou escrava em seus processos produtivos, assim como não deve permitir a contratação deste tipo de mão-de-obra por seus fornecedores. Os mesmos princípios éticos que direcionam a empresa devem ser exigidos de seus fornecedores, de modo a garantir que eles sejam fielmente cumpridos. $O$ ideal é que estas exigências estejam estabelecidas em contratos, e sua efetividade periodicamente verificada.

\section{Considerações finais}

A responsabilidade social e os princípios éticos podem ser vistos hoje como uma nova forma de gestão, um instrumento para melhorar e consolidar a imagem das organizações perante as comunidades, para a abertura de novos mercados e maior competitividade nas transações globalizadas. Várias empresas, em nível mundial, já têm uma visão ampliada deste cenário, com ações para melhorar o bem estar da comunidade em que está inserida, reduzir os impactos sobre o meio ambiente, aumentar os diálogos com os colaboradores, enfim, com todos os seus stakeholders. O desempenho econômico torna-se dinâmico e estratégico com os investimentos nestas áreas e trazendo importantes retornos financeiros e sociais para os envolvidos.

Observa-se no atual cenário que as oportunidades do mercado tendem a privilegiar os produtos e serviços oriundos de empresas com condutas sustentáveis. Sendo a responsabilidade social um dos pilares da sustentabilidade, é possível estabelecer um diferencial frente aos concorrentes haja vista a importância deste tipo de investimento que gera uma imagem forte para a empresa, boa visibilidade, e pode transformar-se em benefícios sociais. 
Quanto à análise das ações voltadas à Responsabilidade Social nas indústrias de móveis de um município do interior de Santa Catarina, situadas no maior parque fabril do estado no segmento moveleiro (PORTAL TURISMO, 2010), e parte do maior pólo exportador de móveis do Brasil (VERAS, 2007, p.28), a pesquisa revelou que as ações empresariais relacionadas às práticas apresentaram-se ainda em um estágio prematuro, carecendo de maior conscientização e de ferramentas de gestão apropriadas.

Verificou-se que as práticas sociais realizadas por estas empresas estão relacionadas as suas obrigações legais, destinando-se ao cumprimento das exigências relacionadas à existência destas. Este fato é bastante negativo, pois demonstra o pouco engajamento destas empresas na difusão e na prática da responsabilidade social propriamente dita. Por exemplo, a falta de comprometimento com o desenvolvimento da comunidade, revelada pelas respostas negativas das empresas, representa falta apoio aos projetos focados nas crianças e adolescentes das comunidades do entorno. Além disso, não há projetos para o desenvolvimento dos filhos dos colaboradores e nem políticas para erradicação do trabalho infantil ou forçado.

Mas alguns pontos positivos também merecem destaque, como o fato de mais da metade das empresas pesquisadas afirmarem possuir código de ética e o divulgarem para seus diferentes níveis hierárquicos, e o incorporarem em sua cultura. Porém, os dados positivos são relativamente poucos, e indicam que as práticas desenvolvidas por estas empresas ainda têm um longo caminho a ser trilhado no sentido de inserir os pressupostos de responsabilidade social nas formas de gestão empresarial.

Pela pesquisa bibliográfica e pela pesquisa de campo foi possível verificar como as ações sobre a Responsabilidade Social nas empresas produtoras de móveis de um município do interior de Santa Catarina necessitam de pessoas especializadas para criar novos procedimentos para as atividades produtivas e dedicarem-se à elaboração de ferramentas de gestão mais sistêmicas e alinhadas ao desenvolvimento sustentável.

\section{Notas}

1 O termo "obrigações" está sendo usado aqui no sentido informal e descritivo.

2 Stakeholders é um termo apropriado diretamente da língua inglesa e quer dizer "pessoas ou organizações comprometidas com o planejamento estratégico das empresas".

\section{Referências}

ASHLEY, P. A. (coordenadora) Ética e Responsabilidade Social nos Negócios. 2a . Ed., São Paulo: Saraiva, 2005.

BORBA, P. R. F. Relação entre Desempenho Social Corporativo e Desempenho Financeiro de Empresas no Brasil, 2005. Dissertação (Mestrado em Administração), Universidade de São Paulo, 2005. 
CAVALCANTI, M. (organizadora). Gestão Social, estratégias e parcerias: redescobrindo a essência da administração brasileira de comunidades para o Terceiro Setor. São Paulo: Saraiva, 2006.

DONAIRE, D. Gestão Ambiental na Empresa. 2a. ed., São Paulo: Atlas, 1999.

FACHIN, O. Fundamentos de Metodologia. 4.ed., São Paulo: Saraiva, 2005.

FEDATO, M. C. L. Responsabilidade Social Corporativa: Benefício Social ou Vantagem Competitiva - Um estudo das estratégias de atuação social empresarial e sua avaliação de resultados, 2005. Dissertação (Mestrado em Administração), Universidade de São Paulo. São Paulo, 2005.

GIL, A. C. Como elaborar projetos de pesquisa. 4.ed., São Paulo: Atlas, 2002.

INSTITUTO ETHOS. Ética e qualidade nas relações. Disponível em: <http://www.ethos.org.br/docs/conceitos_praticas/indicadores/responsabilida de/etica.asp>. Acesso em: 01 out. 2010.

INSTITUTO ETHOS. Valores, transparência e governança. Disponível em:<http://www.ethos.org.br/docs/conceitos_praticas/indicadores/temas/valo res1.asp>. Acesso em: 17 jan. 2011.

LABOISSIÈRE, P.; CAVALCANTE, T. Relatório do PNUD: Brasil é o terceiro país mais desigual da América Latina e do Caribe. Disponível em: <http://www.observatoriosocial.org.br>. Publicado em 23 jul. 2010. Acesso em: 28 set. 2010.

LAKATOS, E. M.; MARCONI, M. A. Técnicas de Pesquisa. 6.ed., São Paulo: Atlas, 2006.

MELO NETO, F. P.; FROES, C. Responsabilidade Social \& Cidadania Empresarial: a Administração do Terceiro Setor. Rio de Janeiro: Qualitymark, 1999.

MENEZES, E. M. e SILVA, E. L. Metodologia da Pesquisa e Elaboração de Dissertação. 4.ed., rev. Atual, Florianópolis: laboratório de ensino a distância da UFSC, 2005.

PORTAL TURISMO. Municípios de Santa Catarina. Disponível em: <http://www.sc.gov.br/portalturismo> Acesso em: 26 out. 2010.

SANTOS, A. S. R. Homem-Natureza: a nova relação ética. Disponível em: <http://www.scribd.com/doc/4489399/HomemNatureza-a-nova-relacaoetica> Acesso em: 17 mar. 2010. 
SEBRAE - Serviço Brasileiro de Apoio às Micro e Pequenas Empresas. Critérios de classificação de empresas. Disponível em: <http://www.sebraesc.com.br/leis/default.asp?vcdtexto=4154\&\%5E \%5E>. Acesso em: 10 jan. 2011.

VERAS, D. Madeira e Sangue. Disponível em: <http://www.observatoriosocial.org.br>. Publicado em: out. 2007. Acesso em: 26 set. 2010.

ZARPELON, M. I. Gestão e Responsabilidade Social: NBR 16.001/AS 8.000: implantação e prática. Rio de Janeiro: Qualitymark, 2006. 